\title{
An amino-terminal BRAF deletion accounting for acquired resistance to RAF/EGFR inhibition in colorectal cancer
}

\author{
Jack K. Tung, ${ }^{1}$ Nastaran Neishaboori, ${ }^{2}$ Sigurdis Haraldsdottir, ${ }^{3,4}$ \\ and Carlos J. Suarez ${ }^{1}$ \\ ${ }^{1}$ Department of Pathology, Stanford University School of Medicine, Stanford, California 94305, USA; \\ ${ }^{2}$ Adaptive Biotechnologies, Seattle, Washington 98102, USA; ${ }^{3}$ Department of Oncology, Dana-Farber Cancer \\ Institute, Boston, Massachusetts 02215, USA; ${ }^{4}$ Department of Medicine-Oncology, Stanford University \\ School of Medicine, Stanford, California 94305, USA
}

Abstract Although combination therapy with RAF and EGFR inhibitors has improved the survival outcomes of patients with BRAF-mutated colorectal cancer (CRC), acquired resistance invariably develops. The mechanisms of acquired resistance to RAF inhibitors have been largely attributed to activating mutations in RAS genes, MAP2K mutations, and amplifications in BRAF, RAS genes, and EGFR. In this report, we describe a patient with BRAF-mutated CRC who acquired an amino-terminal BRAF deletion involving the Ras-binding domain (RBD) after treatment with RAF/EGFR inhibitor therapy. Amino-terminal BRAF deletions involving the RBD are a rare mechanism of acquired resistance to RAF inhibitors, particularly in CRC for which there is only one prior report in the literature.

Corresponding author: cjsuarez@stanford.edu; Sigurdis_haraldsdottir@ dfci.harvard.edu

(c) 2020 Tung et al. This article is distributed under the terms of the Creative Commons Attribution-NonCommercial License, which permits reuse and redistribution, except for commercial purposes, provided that the original author and source are credited.

Ontology terms: neoplasm of the gastrointestinal tract; neoplasm of the large intestine

Published by Cold Spring Harbor Laboratory Press

doi:10.1101/mcs.a005140

\section{INTRODUCTION}

Colorectal cancer (CRC) is one of the leading causes of cancer worldwide with an estimated 1.8 million new cases in 2018. Despite a greater understanding of disease mechanisms and advances in treatment options over the last several decades, some patients with CRC still have a relatively poor prognosis and show a limited response to conventional therapy. In particular, CRCs harboring BRAF mutations have a poor response to standard therapies and ultimately develop resistance to currently available targeted therapies.

BRAF is part of the RAF family of serine/threonine kinases and is a component of the mitogen-activated protein kinase (MAPK) signaling pathway. The BRAF protein has two main functional domains: a kinase domain that serves to phosphorylate and activate downstream MEK/ERK signaling and an autoinhibitory domain, where RAS-GTP binds, that serves to inhibit RAF kinase activity. Upstream receptor tyrosine kinase (RTK) activity ultimately leads to Ras-mediated disruption of the autoinhibitory region via recruitment of RAF dimers and phosphorylation of RAF. BRAF mutations are found in 7\%-10\% of patients with metastatic CRC and can confer a poor prognosis (Samowitz et al. 2005; Tol et al. 2009; Roth et al. 2010; Tie et al. 2011). Specifically, the V600E point mutation accounts for nearly $90 \%$ of $B R A F$ mutations seen in CRC and results in a constitutively active kinase domain and subsequent MAPK activation (Cancer Genome Atlas Network 2012). The median survival of 
COLD SPRING HARBOR Molecular Case Studies
Acquired amino-terminal BRAF deletion in CRC

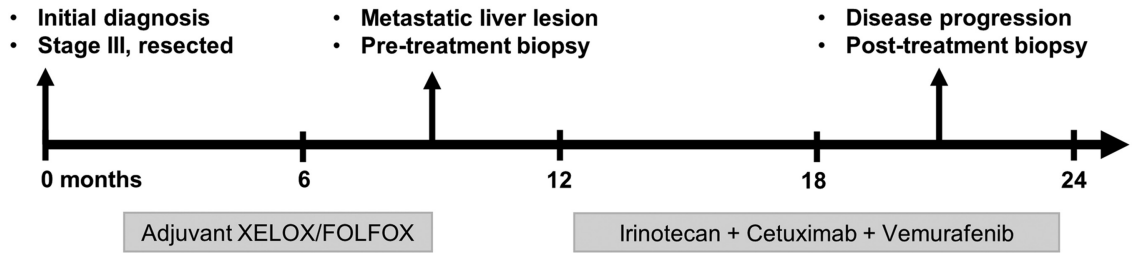

Figure 1. Timeline of events.

patients with metastatic $C R C$ harboring $B R A F^{\mathrm{V} 600 \mathrm{E}}$ mutations is $1 \mathrm{yr}$ compared to $2-3 \mathrm{yr}$ in patients with wild-type BRAF. Non-V600E BRAF mutations have been associated with a more favorable prognosis in metastatic $\mathrm{CRC}$, exhibiting different responses to targeted therapy depending on the functional class of the mutation (Jones et al. 2017; Yaeger et al. 2019).

BRAF inhibitors such as vemurafenib and dabrafenib have been utilized as targeted therapies for V600E-mutated CRC with the initial expectation that they would be as effective as they are with $B R A F^{\mathrm{V} 600 \mathrm{E}}$-mutated melanomas. Unfortunately, vemurafenib monotherapy has produced limited response rates in patients with V600E-mutant metastatic CRC ( $5 \%$ overall response rate compared to $50 \%-80 \%$ in melanoma) as a result of reactivation of EGFR and MAPK signaling (Chapman et al. 2011; Sosman et al. 2012; Corcoran 2015; Kopetz et al. 2015). Combination therapy with EGFR and BRAF inhibitors has therefore been investigated and has shown improved response rates ranging from $4 \%$ to $23 \%$ in various early clinical trials (Geel et al. 2014; Hyman et al. 2015; Yaeger et al. 2015; Tabernero et al. 2016; Desai et al. 2017). Despite these promising results, patients who initially responded to therapy ultimately acquire resistance and develop disease progression. A greater understanding of the mechanisms of acquired resistance is therefore crucial to developing strategies to overcome resistance and prolong the overall survival of patients.

Although a limited number of studies have investigated the resistance mechanisms of $B R A F$-mutated CRC, several in vitro studies have demonstrated that MAPK signaling reactivation is a common feature seen in resistant cell lines. Oddo et al. (2016) demonstrated that MAPK signaling reactivation is achieved via different mechanisms, including amplification of EGFR, KRAS, and BRAF genes as well as acquired mutations in KRAS, EGFR, and MAP2K1. Ahronian et al. (2015) similarly identified various MAPK pathway alterations (KRAS amplification, BRAF amplification MEK1 mutations) as mechanisms of resistance in vitro and in clinical samples. Yaeger et al. (2017) also found various genetic alterations in the MAPK pathway in CRC tumor samples that had progressed on RAF and EGFR inhibitors, with RAS amplification being the most recurrent mechanism of resistance. Although other genomic alterations (e.g., BRAF fusions, splice variants, internal deletions, kinase domain duplications) associated with acquired resistance to BRAF inhibitors have been reported for melanomas and various other tumors (Poulikakos et al. 2011; Rizos et al. 2014; Shi et al. 2014), published reports for CRC are rare. Here, we describe a case in which a large amino-terminal deletion in BRAF was detected in a patient with $C R C$ that had acquired resistance to BRAF and EGFR inhibitors (Fig. 1).

\section{CASE PRESENTATION}

The patient is a 40-yr-old woman who initially presented to the emergency department with a partial large bowel obstruction. Colonoscopy revealed an obstructing mass in the transverse colon with biopsy-proven adenocarcinoma. She underwent partial colectomy, and her pathology showed a well to moderately differentiated invasive adenocarcinoma (pT4a N1a-AJCC eighth edition) with proficient mismatch repair status. She was treated with 
Table 1. Pathogenic and likely pathogenic somatic variants identified in the tumors

\begin{tabular}{|c|c|c|c|c|c|c|}
\hline Gene & $\mathrm{Chr}$ & HGVS DNA reference & $\begin{array}{l}\text { HGVS protein } \\
\text { reference }\end{array}$ & $\begin{array}{l}\text { VAF } \\
\text { (\%) }\end{array}$ & Coverage & Predicted effect \\
\hline \multicolumn{7}{|c|}{ Pretreatment liver biopsy ( $50 \%$ tumor content); median exon coverage: $963 \times$} \\
\hline$B R A F$ & 7 & NM_004333.4:c.1799T>A & p.(Val600Glu) & 24.0 & 1000 & Nonsynonymous SNV \\
\hline PIK3CA & 3 & NM_006218.2:c.1258T>C & p.(Cys420Arg) & 27.7 & 877 & Nonsynonymous SNV \\
\hline TP53 & 17 & NM_000546.5:c.527G>T & p.(Cys176Phe) & 32.8 & 922 & Nonsynonymous SNV \\
\hline SMAD4 & 18 & $\begin{array}{l}\text { NG_013013.2(NM_005359.6): c.(-129+1_-128-1) } \\
\quad\left(424+1 \_425-1\right) \text { dup }\end{array}$ & p.(Asp142fs) & $\mathrm{n} / \mathrm{a}$ & $\mathrm{n} / \mathrm{a}$ & Duplication exon 2-3 \\
\hline PTEN & 10 & $\mathrm{n} / \mathrm{a}$ & $\mathrm{n} / \mathrm{a}$ & $\mathrm{n} / \mathrm{a}$ & $\mathrm{n} / \mathrm{a}$ & Whole gene deletion \\
\hline \multicolumn{7}{|c|}{ Post-treatment abdominal wall biopsy (30\% tumor content); median exon coverage: $393 \times$} \\
\hline BRAF & 7 & NM_004333.4:c.1799T>A & p.(Val600Glu) & 20.0 & 365 & Nonsynonymous SNV \\
\hline PIK3CA & 3 & NM_006218.2:c.1258T>C & p.(Cys420Arg) & 19.5 & 334 & Nonsynonymous SNV \\
\hline TP53 & 17 & NM_000546.5:c.527G>T & p.(Cys176Phe) & 29.6 & 449 & Nonsynonymous SNV \\
\hline SMAD4 & 18 & $\begin{array}{l}\text { NG_013013.2(NM_005359.6): c.(-129+1_-128-1) } \\
\quad\left(424+1 \_425-1\right) \text { dup }\end{array}$ & p.(Asp142fs) & $\mathrm{n} / \mathrm{a}$ & $n / a$ & Duplication exon 2-3 \\
\hline CUL4A & 13 & $\mathrm{n} / \mathrm{a}$ & $\mathrm{n} / \mathrm{a}$ & $\mathrm{n} / \mathrm{a}$ & $\mathrm{n} / \mathrm{a}$ & Amplification \\
\hline BRAF & 7 & $\begin{array}{l}\text { NG_007873.3(NM_004333.4):c.(138+1_139-1)_ } \\
\quad\left(1314+1 \_1315-1\right) \text { del }\end{array}$ & p.(Val47_Met438del) & $\mathrm{n} / \mathrm{a}$ & $\mathrm{n} / \mathrm{a}$ & Deletion exon 2-10 \\
\hline
\end{tabular}

(HGVS) Human Genome Variation Society, (VAF) variant allele fraction, (SNV) single-nucleotide variant; (n/a) not available.

two cycles of capecitabine and oxaliplatin followed by eight cycles of leucovorin, fluorouracil, and oxaliplatin (switched because of poor tolerance), but CEA levels rose 7 mo later and imaging showed a new liver nodule. Then, she underwent partial hepatectomy for a 2-cm lesion consistent with metastatic adenocarcinoma by histopathology. DNA analysis of the liver lesion by a 324-gene next-generation sequencing (NGS) assay revealed BRAF ${ }^{\mathrm{V} 600 \mathrm{E}}$, TP53 ${ }^{\mathrm{C} 176 \mathrm{~F}}$, PIK3CA ${ }^{\mathrm{C} 420 \mathrm{R}}$, PTEN loss, and a SMAD4 exons 2-3 duplication (Table 1). CEA levels continued to rise over the next $2 \mathrm{mo}$ and imaging revealed new peritoneal, abdominal wall, portacaval lymph node, and ovarian metastases. Patient transferred care to Stanford and was started on irinotecan and cetuximab initially in early 2018 with vemurafenib added several weeks later given the BRAF mutation detected in the liver specimen. The patient had rapid clinical improvement with notable shrinkage in palpable abdominal wall nodules and improvement in pain. Surveillance imaging showed a partial response until 6 mo later when enlarging abdominal wall masses were identified. Computed tomography (CT)-guided biopsy of one of the masses confirmed metastasis, and a new BRAF exon 2-10 deletion and CUL4A amplification was detected by DNA analysis using the same 324-gene NGS assay (Table 1). Irinotecan, cetuximab, and vemurafenib treatment was continued while the patient received palliative radiation therapy to the abdominal wall. Following recommendation from the molecular tumor board, cobimetinib, a MEK inhibitor, was added to her treatment 2 mo later through compassionate use. However, given disease progression, she was transitioned to hospice care soon after.

\section{DISCUSSION}

The BRAF exon 2-10 deletion identified in the peritoneal mass after treatment with vemurafenib involves deletion of the amino-terminal autoinhibitory region (CR1), which includes the Ras-binding domain (RBD) (Fig. 2B). Amino-terminal BRAF deletions are uncommon 
COLD SPRING HARBOR Molecular Case Studies
Acquired amino-terminal BRAF deletion in CRC

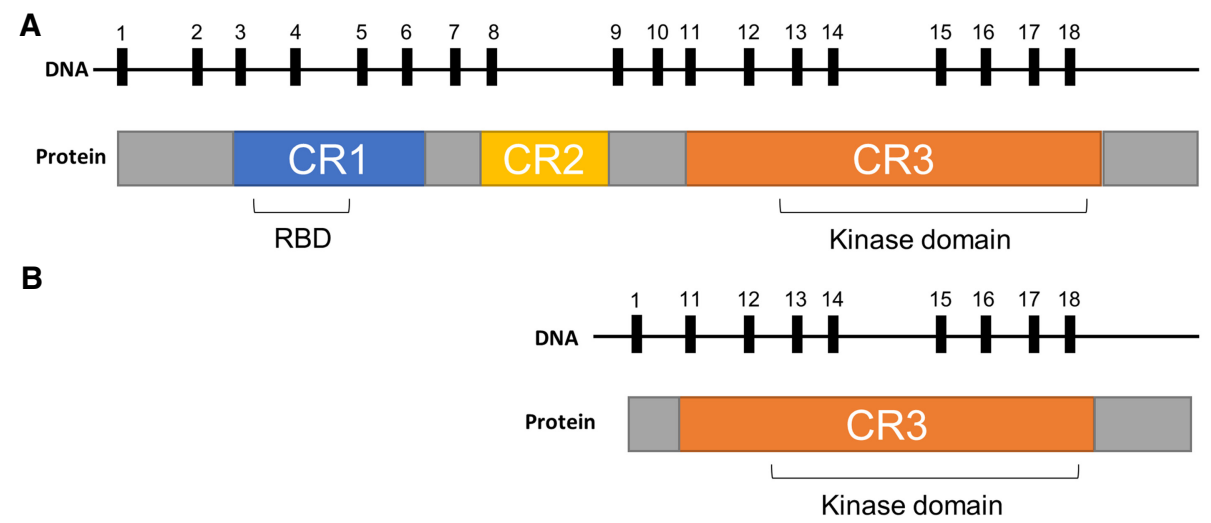

Figure 2. Schematic of wild-type BRAF gene $(A)$ and BRAF exon 2-8 deletion (B). Exon numbers are shown above their corresponding protein products, with relevant functional domains labeled. (RBD) Ras-binding domain, (CR) conserved region.

alterations and have been mostly identified in metastatic melanoma, with fewer reports in other tumor types such as multiple myeloma, glioblastoma, and adenocarcinoma (lung, pancreas, and prostate) (Rizos et al. 2014; Johnson et al. 2018). Although there is currently no in vitro experimental evidence determining the precise effect of amino-terminal BRAF deletions removing the RBD, they are predicted to drive acquired resistance to BRAF inhibitors via Ras-independent constitutive dimerization and activation of the truncated RAF. This mechanism is predicted to be analogous to the loss of RBD by alternative splicing (Poulikakos et al. 2011) or gene fusions (Palanisamy et al. 2010; Hutchinson et al. 2013; Ross et al. 2016; Kulkarni et al. 2017), which are better studied mechanisms.

The mechanisms of resistance to RAF inhibitors in CRC have been largely attributed to mutant BRAF amplifications, RAS amplifications, EGFR amplifications, activating RAS mutations, and MAP2K1 mutations (Oddo et al. 2016; Yaeger et al. 2017). The case presented herein provides supporting evidence that resistance to RAF inhibition can also result from amino-terminal BRAF deletions. To the best of our knowledge, there has only been one other previously reported amino-terminal BRAF deletion in CRC. Yaeger et al. reported one patient with metastatic BRAF mutant CRC who eventually progressed on encorafenib, cetuximab, and alpelisib (Yaeger et al. 2017). The patient had a partial response to this combination therapy (62\% response by RECIST) for 24 wk before acquiring a BRAF exon 2-8 deletion in a peritoneal metastasis and NRAS mutation in a liver metastasis.

Acquired resistance to combination therapy has been long thought to result from multiple mechanisms working in concert. In one study, amino-terminal BRAF deletions involving the RBD have been described with concurrent $B R A F^{\mathrm{V} 600 \mathrm{E}}$ mutations in the majority (90\%) of melanomas, but less so (44\%) with other tumor types (Johnson et al. 2018). Interestingly, in $C R C$, both the case described in this report and the case reported by Yaeger et al. harbored a $B R A F^{\mathrm{V} 600 \mathrm{E}}$ along with the amino-terminal BRAF deletion. The patient also developed a CUL4A amplification in her post-BRAF inhibitor treatment specimen, which has been shown to promote proliferation and metastasis of CRC cells in vitro (Sui et al. 2017). Finally, the patient's preexisting PTEN loss and PI3K mutations may have also primed the patient for developing RAF inhibitor resistance as these alterations have been associated with resistance in preclinical models (Paraiso et al. 2011; Xing et al. 2012) and decreased response duration in patients with melanoma (Nathanson et al. 2013).

The approach to treating CRC is rapidly evolving as our understanding of resistance mechanisms to targeted therapy continues to grow. Clinical trials investigating combination 
therapies targeting EGFR, RAF, and MEK are ongoing and have shown encouraging results (Hong et al. 2016; Corcoran et al. 2018; Ursem et al. 2018; Kopetz et al. 2019). With recent evidence supporting the notion that RAF dimerization may be a common feature of the mechanism of acquired resistance to RAF inhibitors in CRC (Yaeger et al. 2017), novel RAF dimer inhibitors have also been evaluated in this context and have been shown to be effective in inhibiting growth of RAF/EGFR inhibitor resistant cells in vitro (Yaeger et al. 2017; Yao et al. 2019). Although it may be safe to assume that amino-terminal BRAF deletions represent class II mutations that function as RAS-independent activated dimers, further characterization of this rare alteration is needed in order to guide effective targeted therapy strategies in the future.

\section{METHODS}

The specimens obtained from our patient were sequenced by the FoundationOne CDx (F1CDx) assay. An amount of 50-1000 ng of extracted DNA is subjected to whole-genome shotgun library construction and hybridization-based capture of all coding exons from 309 cancer-related genes, one promoter region, one noncoding RNA (ncRNA), and select intronic regions from 34 commonly rearranged genes, 21 of which also include the coding exons. In total, the assay detects alterations in a total of 324 genomic regions. Using the Illumina HiSeq 4000 platform, hybrid capture-selected libraries are sequenced to high uniform depth (targeting $>500 \times$ median coverage with $>99 \%$ of exons at coverage $>100 \times$ ). Sequence data is then processed using a customized analysis pipeline designed to detect all classes of genomic alterations, including base substitutions, indels, copy-number alterations (amplifications and homozygous gene deletions), and selected genomic rearrangements (e.g., gene fusions). Additionally, genomic signatures including microsatellite instability (MSI) and tumor mutational burden (TMB) are reported.

\section{ADDITIONAL INFORMATION}

\section{Data Deposition and Access}

The interpreted variants have been deposited to the Catalog of Somatic Mutations in Cancer (COSMIC) database (https://cancer.sanger.ac.uk/cosmic) under the identifier COSP48265. Consent could not be obtained to make the raw sequence data publicly available.

\section{Ethics Statement}

The patient information has been appropriately de-identified in accordance with regulatory requirements.

\section{Acknowledgments}

Competing Interest Statement

The authors have declared no competing interest.

Received January 10, 2020; accepted in revised form May 5, 2020.
We are grateful to the patient who allowed us to participate in her care.

\section{Author Contributions}

All authors contributed to conception and design, collection and assembly of data, data analysis and interpretation, manuscript writing, and final approval of manuscript. S.H. provided the patient's information. 


\section{REFERENCES}

Ahronian LG, Sennott EM, Van Allen EM, Wagle N, Kwak EL, Faris JE, Godfrey JT, Nishimura K, Lynch KD, Mermel $\mathrm{CH}$, et al. 2015. Clinical acquired resistance to RAF inhibitor combinations in BRAF-mutant colorectal cancer through MAPK pathway alterations. Cancer Discov 5: 358-367. doi:10.1158/2159-8290 CD-14-1518

Cancer Genome Atlas Network. 2012. Comprehensive molecular characterization of human colon and rectal cancer. Nature 487: 330-337. doi:10.1038/nature11252

Chapman PB, Hauschild A, Robert C, Haanen JB, Ascierto P, Larkin J, Dummer R, Garbe C, Testori A, Maio M, et al. 2011. Improved survival with vemurafenib in melanoma with BRAF V600E mutation. N Engl J Med 364: 2507-2516. doi:10.1056/NEJMoa1103782

Corcoran RB. 2015. New therapeutic strategies for BRAF mutant colorectal cancers. J Gastrointest Oncol 6: 650-659. doi:10.3978/j.issn.2078-6891.2015.076

Corcoran RB, André T, Atreya CE, Schellens JHM, Yoshino T, Bendell JC, Hollebecque A, McRee AJ, Siena S, Middleton G, et al. 2018. Combined BRAF, EGFR, and MEK inhibition in patients with BRAF ${ }^{\mathrm{V} 600 \mathrm{E}}$-mutant colorectal cancer. Cancer Discov 8: 428-443. doi:10.1158/2159-8290.CD-17-1226

Desai J, Markman B, Ananda S, Tebbutt NC, Michael M, Solomon BJ, McArthur GA, Tie J, Gibbs P, Ritchie D, et al. 2017. A phase I/II trial of combined BRAF and EGFR inhibition in patients (Pts) with BRAF V600E mutated (BRAFm) metastatic colorectal (MCRC): the EViCT (Erlotinib and Vemurafenib in Combination Trial) study. J Clin Oncol 35: 3557. doi:10.1200/JCO.2017.35.15_suppl.3557

Geel RV, Elez E, Bendell JC, Faris JE, Lolkema MPJK, Eskens F, Spreafico A, Kavan P, Delord J-P, Schuler MH, et al. 2014. Phase I study of the selective $B R A F^{V 600}$ inhibitor encorafenib (LGX818) combined with cetuximab and with or without the $\alpha$-specific PI3K inhibitor BYL719 in patients with advanced BRAF-mutant colorectal cancer. J Clin Oncol 32: 3514. doi:10.1200/jco.2014.32.15_suppl.3514

Hong DS, Morris VK, Osta BE, Sorokin AV, Janku F, Fu S, Overman MJ, Piha-Paul S, Subbiah V, Kee B, et al. 2016. Phase IB study of vemurafenib in combination with irinotecan and cetuximab in patients with metastatic colorectal cancer with BRAF ${ }^{\mathrm{V} 600 \mathrm{E}}$ mutation. Cancer Discov 6: 1352-1365. doi:10.1158/2159-8290 CD-16-0050

Hutchinson KE, Lipson D, Stephens PJ, Otto G, Lehmann BD, Lyle PL, Vnencak-Jones CL, Ross JS, Pietenpol JA, Sosman JA, et al. 2013. BRAF fusions define a distinct molecular subset of melanomas with potential sensitivity to MEK inhibition. Clin Cancer Res 19: 6696-6702. doi:10.1158/1078-0432 .CCR-13-1746

Hyman DM, Puzanov I, Subbiah V, Faris JE, Chau I, Blay J-Y, Wolf J, Raje NS, Diamond EL, Hollebecque A, et al. 2015. Vemurafenib in multiple nonmelanoma cancers with BRAFV600 mutations. N Engl J Med 373: 726736. doi:10.1056/NEJMoa1502309

Johnson DB, Childress MA, Chalmers ZR, Frampton GM, Ali SM, Rubinstein SM, Fabrizio D, Ross JS, Balasubramanian S, Miller VA, et al. 2018. BRAF internal deletions and resistance to BRAF/MEK inhibitor therapy. Pigment Cell Melanoma Res 31: 432-436. doi:10.1111/pcmr.12674

Jones JC, Renfro LA, Al-Shamsi HO, Schrock AB, Rankin A, Zhang BY, Kasi PM, Voss JS, Leal AD, Sun J, et al. 2017. Non-V600 BRAF mutations define a clinically distinct molecular subtype of metastatic colorectal cancer. J Clin Oncol 35: 2624-2630. doi:10.1200/JCO.2016.71.4394

Kopetz S, Desai J, Chan E, Hecht JR, O'Dwyer PJ, Maru D, Morris V, Janku F, Dasari A, Chung W, et al. 2015. Phase II pilot study of vemurafenib in patients with metastatic BRAF-mutated colorectal cancer. J Clin Oncol 33: 4032-4038. doi:10.1200/JCO.2015.63.2497

Kopetz S, Grothey A, Yaeger R, Van Cutsem E, Desai J, Yoshino T, Wasan H, Ciardiello F, Loupakis F, Hong YS, et al. 2019. Encorafenib, binimetinib, and cetuximab in BRAF V600E-mutated colorectal cancer. N Engl J Med 381: 1632-1643. doi:10.1056/NEJMoa1908075

Kulkarni A, Al-Hraishawi H, Simhadri S, Hirshfield KM, Chen S, Pine S, Jeyamohan C, Sokol L, Ali S, Teo ML, et al. 2017. BRAF fusion as a novel mechanism of acquired resistance to vemurafenib in $B R A F^{\mathrm{V} 600 \mathrm{E}}$ mutant melanoma. Clin Cancer Res 23: 5631-5638. doi:10.1158/1078-0432.CCR-16-0758

Nathanson KL, Martin A-M, Wubbenhorst B, Greshock J, Letrero R, D'Andrea K, O'Day S, Infante JR, Falchook GS, Arkenau H-T, et al. 2013. Tumor genetic analyses of patients with metastatic melanoma treated with the BRAF inhibitor dabrafenib (GSK2118436). Clin Cancer Res 19: 4868-4878. doi:10.1158/1078-0432 .CCR-13-0827

Oddo D, Sennott EM, Barault L, Valtorta E, Arena S, Cassingena A, Filiciotto G, Marzolla G, Elez E, van Geel RMJM, et al. 2016. Molecular landscape of acquired resistance to targeted therapy combinations in BRAFmutant colorectal cancer. Cancer Res 76: 4504-4515. doi:10.1158/0008-5472.CAN-16-0396

Palanisamy N, Ateeq B, Kalyana-Sundaram S, Pflueger D, Ramnarayanan K, Shankar S, Han B, Cao Q, Cao X, Suleman K, et al. 2010. Rearrangements of the RAF kinase pathway in prostate cancer, gastric cancer and melanoma. Nat Med 16: 793-798. doi:10.1038/nm.2166 
Paraiso KHT, Xiang Y, Rebecca VW, Abel EV, Ann Chen Y, Cecilia Munko A, Wood E, Fedorenko IV, Sondak VK, Anderson ARA, et al. 2011. PTEN loss confers BRAF inhibitor resistance to melanoma cells through the suppression of BIM expression. Cancer Res 71: 2750-2760. doi:10.1158/0008-5472.CAN-10-2954

Poulikakos PI, Persaud Y, Janakiraman M, Kong X, Ng C, Moriceau G, Shi H, Atefi M, Titz B, Gabay MT, et al. 2011. RAF inhibitor resistance is mediated by dimerization of aberrantly spliced BRAF(V600E). Nature 480: 387-390. doi:10.1038/nature10662

Rizos H, Menzies AM, Pupo GM, Carlino MS, Fung C, Hyman J, Haydu LE, Mijatov B, Becker TM, Boyd SC, et al. 2014. BRAF inhibitor resistance mechanisms in metastatic melanoma: spectrum and clinical impact. Clin Cancer Res 20: 1965-1977. doi:10.1158/1078-0432.CCR-13-3122

Ross JS, Wang K, Chmielecki J, Gay L, Johnson A, Chudnovsky J, Yelensky R, Lipson D, Ali SM, Elvin JA, et al. 2016. The distribution of BRAF gene fusions in solid tumors and response to targeted therapy. Int J Cancer 138: 881-890. doi:10.1002/ijc.29825

Roth AD, Tejpar S, Delorenzi M, Yan P, Fiocca R, Klingbiel D, Dietrich D, Biesmans B, Bodoky G, Barone C, et al. 2010. Prognostic role of KRAS and BRAF in stage II and III resected colon cancer: results of the translational study on the PETACC-3, EORTC 40993, SAKK 60-00 trial. J Clin Oncol 28: 466-474. doi:10.1200/ JCO.2009.23.3452

Samowitz WS, Sweeney C, Herrick J, Albertsen H, Levin TR, Murtaugh MA, Wolff RK, Slattery ML. 2005. Poor survival associated with the BRAF V600E mutation in microsatellite-stable colon cancers. Cancer Res 65: 6063-6069. doi:10.1158/0008-5472.CAN-05-0404

Shi H, Hugo W, Kong X, Hong A, Koya RC, Moriceau G, Chodon T, Guo R, Johnson DB, Dahlman KB, et al. 2014. Acquired resistance and clonal evolution in melanoma during BRAF inhibitor therapy. Cancer Discov 4: 80-93. doi:10.1158/2159-8290.CD-13-0642

Sosman JA, Kim KB, Schuchter L, Gonzalez R, Pavlick AC, Weber JS, McArthur GA, Hutson TE, Moschos SJ, Flaherty KT, et al. 2012. Survival in BRAF V600-mutant advanced melanoma treated with vemurafenib. $N$ Engl J Med 366: 707-714. doi:10.1056/NEJMoa1112302

Sui X, Zhou H, Zhu L, Wang D, Fan S, Zhao W. 2017. CUL4A promotes proliferation and metastasis of colorectal cancer cells by regulating H3K4 trimethylation in epithelial-mesenchymal transition. OncoTargets Ther 10: 735-743. doi:10.2147/OTT.S118897

Tabernero J, Van Geel R, Guren TK, Yaeger RD, Spreafico A, Faris JE, Yoshino T, Yamada Y, Kim TW, Bendell JC, et al. 2016. Phase 2 results: Encorafenib (ENCO) and Cetuximab (CETUX) with or without Alpelisib (ALP) in patients with advanced BRAF-mutant colorectal cancer (BRAFm CRC). J Clin Oncol 34: 3544. doi:10 .1200/JCO.2016.34.15_suppl.3544

Tie J, Gibbs P, Lipton L, Christie M, Jorissen RN, Burgess AW, Croxford M, Jones I, Langland R, Kosmider S, et al. 2011. Optimizing targeted therapeutic development: analysis of a colorectal cancer patient population with the BRAF ${ }^{\mathrm{V} 600 \mathrm{E}}$ mutation. Int J Cancer 128: 2075-2084. doi:10.1002/ijc.25555

Tol J, Nagtegaal ID, Punt CJA. 2009. BRAF mutation in metastatic colorectal cancer. N Engl J Med 361: 98-99. doi:10.1056/NEJMc0904160

Ursem C, Atreya CE, Van Loon K. 2018. Emerging treatment options for BRAF-mutant colorectal cancer. Gastrointest Cancer 8: 13-23. doi:10.2147/gictt.s125940

Xing F, Persaud Y, Pratilas CA, Taylor BS, Janakiraman M, She Q-B, Gallardo H, Liu C, Merghoub T, Hefter B, et al. 2012. Concurrent loss of the PTEN and RB1 tumor suppressors attenuates RAF dependence in melanomas harboring (V600E)BRAF. Oncogene 31: 446-457. doi:10.1038/onc.2011.250

Yaeger R, Cercek A, O’Reilly EM, Reidy DL, Kemeny N, Wolinsky T, Capanu M, Gollub MJ, Rosen N, Berger MF, et al. 2015. Pilot trial of combined BRAF and EGFR inhibition in BRAF-mutant metastatic colorectal cancer patients. Clin Cancer Res 21: 1313-1320. doi:10.1158/1078-0432.CCR-14-2779

Yaeger R, Yao Z, Hyman DM, Hechtman JF, Vakiani E, Zhao HY, Su W, Wang L, Joelson A, Cercek A, et al. 2017. Mechanisms of acquired resistance to BRAF V600E inhibition in colon cancers converge on RAF dimerization and are sensitive to its inhibition. Cancer Res 77: 6513-6523. doi:10.1158/0008-5472.CAN-17-0768

Yaeger R, Kotani D, Mondaca S, Parikh AR, Bando H, Van Seventer EE, Taniguchi H, Zhao H, Thant CN, de Stanchina E, et al. 2019. Response to anti-EGFR therapy in patients with BRAF non-V600-mutant metastatic colorectal cancer. Clin Cancer Res 25: 7089-7097. doi:10.1158/1078-0432.CCR-19-2004

Yao Z, Gao Y, Su W, Yaeger R, Tao J, Na N, Zhang Y, Zhang C, Rymar A, Tao A, et al. 2019. RAF inhibitor PLX8394 selectively disrupts BRAF dimers and RAS-independent BRAF-mutant-driven signaling. Nat Med 25: 284-291. doi:10.1038/s41591-018-0274-5 


\section{COLD SPRING HARBOR Molecular Case Studies}

\section{An amino-terminal BRAF deletion accounting for acquired resistance to RAF/EGFR inhibition in colorectal cancer}

Jack K. Tung, Nastaran Neishaboori, Sigurdis Haraldsdottir, et al.

Cold Spring Harb Mol Case Stud 2020, 6: a005140 originally published online July 15, 2020

Access the most recent version at doi: $10.1101 / \mathrm{mcs} . a 005140$

References This article cites 36 articles, 17 of which can be accessed free at: http://molecularcasestudies.cshlp.org/content/6/4/a005140.full.html\#ref-list-1

License This article is distributed under the terms of the Creative Commons

Attribution-NonCommercial License, which permits reuse and redistribution, except for commercial purposes, provided that the original author and source are credited.

Email Alerting Receive free email alerts when new articles cite this article - sign up in the box at the Service top right corner of the article or click here. 